\title{
Strictly linear polyethylene using Co-catalysts chelated by fused bis(arylimino)pyridines: probing ortho-cycloalkyl ring-size effects on molecular weight
}

\section{Hongyi Suo, ${ }^{\text {a,b }}$ Ivan I. Oleynik, ${ }^{c^{*}}$ Chantsalnyam Bariashir, ${ }^{\mathrm{a}, \mathrm{b}}$ Irina V. Oleynik, ${ }^{\mathrm{c}} \mathrm{Zheng}$ Wang, ${ }^{\text {a,b }}$ Gregory A. Solan, ${ }^{* a, d}$ Yanping Ma, ${ }^{a}$ Tongling Liang and Wen-Hua Sun ${ }^{a, b *}$}

${ }^{a}$ Key Laboratory of Engineering Plastics and Beijing National Laboratory for Molecular Sciences, Institute of Chemistry, Chinese Academy of Sciences, Beijing 100190, China.

${ }^{\mathrm{b}}$ CAS Research/Education Center for Excellence in Molecular Sciences, University of Chinese Academy of Sciences, Beijing 100049, China.

${ }^{c}$ N.N. Vorozhtsov Novosibirsk Institute of Organic Chemistry, Pr. Lavrentjeva 9, Novosibirsk 630090, Russia.

${ }^{d}$ Department of Chemistry, University of Leicester, University Road, Leicester LE1 7RH, UK.

*Correspondence: oleynik@nioch.nsc.ru, gas8@leicester.ac.uk and whsun@iccas.ac.cn

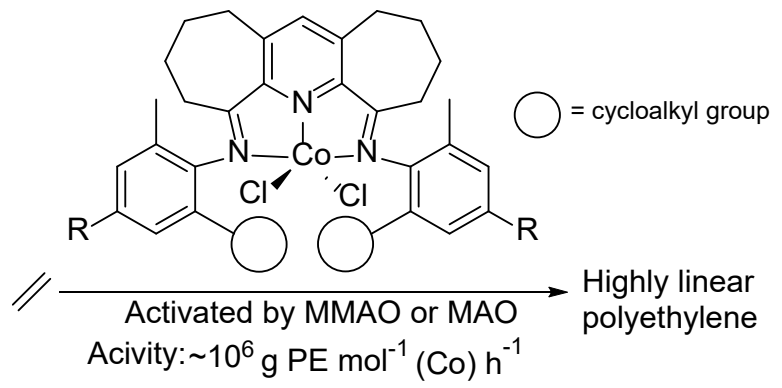

\section{Abstract}

Six examples of $\alpha, \alpha^{\prime}$-bis(arylimino)-2,3:5,6-bis(pentamethylene)pyridine-cobalt(II) chlorides, [2,3:5,6- $\left.\left\{\mathrm{C}_{4} \mathrm{H}_{8} \mathrm{C}(\mathrm{NAr})\right\}_{2} \mathrm{C}_{5} \mathrm{HN}\right] \mathrm{CoCl}_{2}\left(\mathrm{Ar}=2-\left(\mathrm{C}_{5} \mathrm{H}_{9}\right)-6-\mathrm{MeC}_{6} \mathrm{H}_{3} \mathbf{C o 1}, 2-\left(\mathrm{C}_{6} \mathrm{H}_{11}\right)-6-\mathrm{MeC}_{6} \mathrm{H}_{3}\right.$ Co2, 2- $\left(\mathrm{C}_{8} \mathrm{H}_{15}\right)-6-\mathrm{MeC}_{6} \mathrm{H}_{3} \mathbf{C o 3}, 2-\left(\mathrm{C}_{5} \mathrm{H}_{9}\right)-4,6-\mathrm{Me}_{2} \mathrm{C}_{6} \mathrm{H}_{2} \mathbf{C o 4}$, 2- $\left(\mathrm{C}_{6} \mathrm{H}_{11}\right)-4,6-\mathrm{Me}_{2} \mathrm{C}_{6} \mathrm{H}_{2} \mathbf{C o 5}, 2-$ $\left(\mathrm{C}_{8} \mathrm{H}_{15}\right)-4,6-\mathrm{Me}_{2} \mathrm{C}_{6} \mathrm{H}_{2}$ Co6), containing $\mathrm{N}$-aryl groups that differ in either the ring size of the ortho-cycloalkyl substituents or the para- $\mathrm{R}$ group $(\mathrm{R}=\mathrm{H}, \mathrm{Me})$, have been synthesized using a one-pot template approach. The molecular structure of Co1 highlights the ring puckering of both the ortho-cyclopentyl substituents and the two pyridine-fused seven-membered rings; a squarebased pyramidal geometry is conferred about the metal center. On activation with either methylaluminoxane (MAO) or modified MAO (MMAO), all six complexes afforded strictly linear polyethylene (all $T_{\mathrm{m}}$ 's $>130{ }^{\circ} \mathrm{C}$ ) with high molecular weight ( $M_{\mathrm{w}}$ up to 64.3 $\mathrm{kg} \mathrm{mol}^{-1}$ ). Furthermore, all precatalysts displayed high activities (up to $2 \times 10^{6} \mathrm{~g} \mathrm{PE} \mathrm{mol}^{-1}$ (Co) $\mathrm{h}^{-1}$ ) at temperatures between $20-60{ }^{\circ} \mathrm{C}$ with the catalytic activities correlating with the type of ortho-cycloalkyl substituent: cyclohexyl $($ Co2, C05 $)>$ cyclopentyl $($ Co1, Co4 $)>$ cyclooctyl (Co6, Co3) for either $\mathrm{R}=\mathrm{H}$ or Me. The narrow unimodal distributions of the resulting polymers are consistent with single-site active species for the catalysts.

Keywords: linear polyethylene; ortho-cycloalkyl substituent; coordination polymerization 


\section{Introduction}

The use of late transition metal complexes as homogeneous catalysts in alkene oligo/polymerization catalysis has been extensively explored since the mid to late 1990s and remains an active field of research to this day [1-4]. In particular, the ability of bis(imino)pyridine-iron and -cobalt complexes (A, in Chart 1) to mediate the formation of either high density polyethylene or $\alpha$-olefins has provided the impetus for both academic and industrial research [5-8]. While multiple factors influence the performance of the catalyst, the structural features of the bis(arylimino)pyridine ligand are integral allowing control of the catalytic activity and the molecular weight of the oligo-/polymer [9-19]. Of particular note, the positioning of alkyl substituents (e.g., methyl, isopropyl etc.) at the ortho-positions of the two $\mathrm{N}$-aryl groups of the catalyst and the resulting protection of the active species offers a means of regulating the molecular weight of the polymer. Indeed, recognition of such structural features has inspired the development of numerous other compatible N,N,N-ligand sets [20-24]. Common to both iron and cobalt catalysts is a selectivity for highly linear polyethylene, with cobalt catalysts generally showing narrower molecular weight distributions while their iron counterparts display superior activities along with higher molecular weight polymers.

Lately, we have been interested in developing bis(imino)pyridine ligand sets that incorporate fused carbocyclic rings with the intent of introducing structural rigidity to the pincer ligand framework by reducing the flexibility of the exterior imine donors $[8,25]$. With regard to cobalt precatalysts, both singly and doubly fused derivatives with ring sizes of between six and eight are accessible (see for example $\mathbf{B}-\mathbf{E}$, Chart 1) [16,18,25-27]. In terms of catalytic performance, high activities and improved thermal stabilities are a general feature of these systems, while the number of fused rings as well as ring size can be influential on the molecular weights of the olefinic products. For example, using doubly fused $\mathbf{B}$ as the precatalyst (Chart 1) [25], an undesirable mixture of polymers and oligomers are obtained, while use of the singly fused C (Chart 1) [26] leads to solely polymers with narrower molecular weight distribution. Increasing the ring size to seven (D and E, Chart 1) [16,18], results in increased molecular weight which is most apparent 
with doubly-fused E [18].

$<$ Chart 1>

Given the predilection of E-type cobalt precatalysts to form higher molecular weight polyethylene, we wanted to explore how the introduction of more sterically hindered ortho groups would impact on the molecular weight and other properties of the polymer. In particular, we describe the catalytic performance of a series of $\alpha, \alpha^{\prime}$-bis(arylimino)-2,3:5,6bis(pentamethylene)pyridine-cobalt(II) chloride complexes that contain cycloalkyl orthosubstituents of various ring sizes (cyclopentyl vs. cyclohexyl vs. cyclooctyl); electronic variations imparted by different para-R groups $(\mathrm{H}, \mathrm{Me}$ : Chart 1$)$ presents a further feature to be investigated. Elsewhere, ortho-cycloalkyl incorporation has been shown to have some notable effects on catalytic performance and molecular weight which have been correlated with the size of cyclic substituent [28-31]. Full characterization of the complexes and intrinsic properties of the resulting polyethylenes (e.g., molecular weight, distribution, melting temperatures, crystallinity, microstructure and water contact angle) are reported.

\section{Materials and Methods}

\subsection{General considerations}

All manipulations of air- and/or moisture-sensitive compounds were carried out under a nitrogen atmosphere using standard Schlenk techniques. Toluene was refluxed over sodium benzophenone and distilled under nitrogen prior to use. Methylaluminoxane (MAO, 1.46 M solution in toluene) and modified methylaluminoxane (MMAO, 2.0 $\mathrm{M}$ in heptane) were purchased from Akzo Nobel Corp. High-purity ethylene was purchased from Beijing Yansan Petrochemical Co. and used as received. Other reagents were purchased from Aldrich, Acros or local suppliers. IR spectra were recorded on a Perkin-Elmer System 2000 FT-IR spectrometer. Elemental analysis was carried out using a Flash EA 1112 microanalyzer. Molecular weights and molecular weight distributions of the polyethylenes were determined using a PL-GPC220 instrument at $150{ }^{\circ} \mathrm{C}$ with 1,2,4-trichlorobenzene as solvent. Melting temperatures of the polyethylenes were measured from the second scanning run on a Perkin-Elmer DSC-7 
differential scanning calorimeter (DSC) under a nitrogen atmosphere. In the procedure, a sample of about $5.0 \mathrm{mg}$ was heated to $160^{\circ} \mathrm{C}$ at a rate of $20^{\circ} \mathrm{C} / \mathrm{min}$ and kept for $2 \mathrm{~min}$ at $160{ }^{\circ} \mathrm{C}$ to remove the thermal history and then cooled to $20^{\circ} \mathrm{C}$ at a rate of $20{ }^{\circ} \mathrm{C} / \mathrm{min}$. The ${ }^{13} \mathrm{C}$ NMR spectra of the polyethylenes were recorded on a Bruker DMX-300 MHz instrument at $135{ }^{\circ} \mathrm{C}$ in deuterated 1,1,2,2-tetrachloroethane- $d_{2}$ with TMS as an internal standard. The water contact angles (WCAs) were determined using a contact angle tester (Harke-Spcax1). The compounds, $\alpha, \alpha^{\prime}$-dioxo-2,3:5,6-bis(pentamethylene)pyridine $\quad[18], \quad$ 2-cyclopentyl-6-methylaniline hydrochloride, 2-cyclohexyl-6-methylaniline hydrochloride, 2-cyclooctyl-6-methylaniline hydrochloride, 2-cyclopentyl-4,6-dimethylaniline hydrochloride, 2-cyclohexyl-4,6dimethylaniline hydrochloride, 2-cyclooctyl-4,6-dimethylaniline hydrochloride, have been prepared using literature methods [32].

\subsection{Preparation of 2,3:5,6- $\left.\left\{\mathrm{C}_{4} \mathrm{H}_{8} \mathrm{C}(\mathrm{NAr})\right\}_{2} \mathrm{C}_{5} \mathrm{HN}\right] \mathrm{CoCl}_{2}$}

(a) $\mathrm{Ar}=2-\left(\mathrm{C}_{5} \mathrm{H}_{9}\right)-6-\mathrm{MeC}_{6} \mathrm{H}_{3}$ (Co1). A suspension of $\alpha, \alpha^{\prime}$-dioxo-2,3:5,6-bis(pentamethylene) pyridine (0.122 g, $0.5 \mathrm{mmol})$, 2-cyclopentyl-6-methylaniline hydrochloride $(0.212 \mathrm{~g}, 1.0 \mathrm{mmol})$ and $\mathrm{CoCl}_{2}(0.058 \mathrm{~g}, 0.45 \mathrm{mmol})$ in glacial acetic acid $(10 \mathrm{~mL})$ was stirred and heated to reflux for $6 \mathrm{~h}$. On cooling to room temperature, an excess of diethyl ether was added to precipitate the product. The precipitate was then filtered and washed with diethyl ether $(3 \times 15 \mathrm{~mL})$ and dried under reduced pressure to give $\mathbf{C o 1}$ as a green powder (0.18 g, 59\%). FT-IR ( $\left.\mathrm{cm}^{-1}\right)$ : 2921 (s), 2857 (m), 1610 (m), 1582 (m), 1440 (s), 1330 (w), 1250 (m), 1210 (m), 1169 (m), 1132 (m), 1036 (m), 931 (w), 854 (s), 754 (w). $\mathrm{C}_{39} \mathrm{H}_{47} \mathrm{Cl}_{2} \mathrm{CoN}_{3}$ (687.66): calcd. C 68.12, H 6.89, N 6.11\%; found C 68.39, H 6.99, N 6.02\%.

(b) $\mathrm{Ar}=2-\left(\mathrm{C}_{6} \mathrm{H}_{11}\right)-4-\mathrm{MeC}_{6} \mathrm{H}_{3}(\mathbf{C o 2})$. Based on the molar ratios and procedure described for the synthesis of Co1, Co2 was obtained as a green powder (0.14 g, 42\%). FT-IR (cm-1): 2925 (s), 2851 (m), 1608 (m), $1582(\mathrm{~m}), 1447$ (s), $1320(\mathrm{w}), 1250(\mathrm{~m}), 1169$ (m), $1134(\mathrm{~m}), 1036(\mathrm{~m}), 931$

(w), 779 (s). $\mathrm{C}_{41} \mathrm{H}_{51} \mathrm{Cl}_{2} \mathrm{CoN}_{3}$ (715.71): calcd. C 68.81, H 7.18, N 5.87\%; found C 68.50, H 7.09, N $5.78 \%$.

(c) $\mathrm{Ar}=2-\left(\mathrm{C}_{8} \mathrm{H}_{15}\right)-6-\mathrm{MeC}_{6} \mathrm{H}_{3}(\mathbf{C o 3})$. Based on the molar ratios and procedure described for the synthesis of Co1, Co3 was obtained as a green powder (0.22 g, 64\%). FT-IR ( $\left.\mathrm{cm}^{-1}\right)$ : 2937 (s), 
$2851(\mathrm{~m}), 1699(\mathrm{w}), 1609(\mathrm{~m}), 1585(\mathrm{~m}), 1450(\mathrm{~s}), 1340(\mathrm{w}), 1252(\mathrm{~m}), 1191(\mathrm{~m}), 1169(\mathrm{~m}), 1135$ (m), 1035 (m), 929 (w), 776 (s). $\mathrm{C}_{45} \mathrm{H}_{59} \mathrm{Cl}_{2} \mathrm{CoN}_{3}$ (771.82): calcd. C 70.03, H 7.71, N 5.44\%; found C 70.15, H 7.34, N 5.38\%.

(d) $\mathrm{Ar}=2-\left(\mathrm{C}_{5} \mathrm{H}_{9}\right)-4,6-\mathrm{Me}_{2} \mathrm{C}_{6} \mathrm{H}_{2}(\mathbf{C o 4})$. Based on the molar ratios and procedure described for the synthesis of Co1, Co4 was obtained as a green powder $(0.17 \mathrm{~g}, 53 \%)$. FT-IR $\left(\mathrm{cm}^{-1}\right)$ : 2920 (s), 2864 (s), 1609 (m), 1589 (m), 1474 (s), 1448 (s), 1384 (w), 1252 (w), $1167(w), 1132$ (w), 1034 (w), $961(\mathrm{w}), 854(\mathrm{~m}), 755(\mathrm{w}) \cdot \mathrm{C}_{41} \mathrm{H}_{51} \mathrm{Cl}_{2} \mathrm{CoN}_{3}$ (715.71): calcd. C 68.81, H 7.18, N 5.87\%; found C 68.68, H 7.01, N 5.75\%.

(e) $\mathrm{Ar}=2-\left(\mathrm{C}_{6} \mathrm{H}_{11}\right)-4,6-\mathrm{Me}_{2} \mathrm{C}_{6} \mathrm{H}_{2}(\mathbf{C o 5})$. Based on the molar ratios and procedure described for the synthesis of Co1, Co5 was obtained as a green powder $(0.21 \mathrm{~g}, 62 \%)$. FT-IR $\left(\mathrm{cm}^{-1}\right): 3051$ (w), 2851 (m), 1649 (w), 1610 (m), 1560 (m), 1481 (m), 1447 (s), 1339 (w), 1253 (m), 1169 (m), 1129 (m), 1021 (m), 923 (w), 850 (s), 757 (m). $\mathrm{C}_{43} \mathrm{H}_{55} \mathrm{Cl}_{2} \mathrm{CoN}_{3}$ (743.77): calcd. C 69.44, H 7.45, N 5.65\%; found C 69.12, H 7.39, N 5.54\%.

(f) $\mathrm{Ar}=2-\left(\mathrm{C}_{8} \mathrm{H}_{15}\right)-4,6-\mathrm{Me}_{2} \mathrm{C}_{6} \mathrm{H}_{2}(\mathbf{C o 6})$. Based on the molar ratios and procedure described for the synthesis of Co1, Co6 was obtained as a green powder $(0.20 \mathrm{~g}, 55 \%)$. FT-IR $\left(\mathrm{cm}^{-1}\right): 2925$ (s), $2856(\mathrm{~m}), 1603$ (m), $1550(\mathrm{~m}), 1450$ (s), 1340 (m), 1252 (m), 1211 (m), 1168 (m), 1132 (m), 1036 (w), 928 (w), 855 (s), 753 (m). $\mathrm{C}_{47} \mathrm{H}_{63} \mathrm{Cl}_{2} \mathrm{CoN}_{3}$ (799.88): calcd. C 70.58, H 7.94, N 5.25\%; found C 70.77, H 8.05, N 5.11\%.

\subsection{X-ray crystallographic studies}

Single crystals of Co1 suitable for the X-ray diffraction analysis were obtained by layering a dichloromethane solution of the corresponding complex with hexane at room temperature in air. With graphite monochromated Mo-K $\alpha$ radiation $(\lambda=0.71073 \AA)$ at $173(2) \mathrm{K}$, cell parameters were obtained by global refinement of the positions of all collected reflections. Intensities were corrected for Lorentz and polarization effects and empirical absorption. The structures were solved by direct methods and refined by full-matrix least squares on $F^{2}$. All hydrogen atoms were placed in calculated positions. Structure solution and structure refinement were performed by using the SHELXT (Sheldrick, 2015) [33,34]. The disorder displayed by the cycloheptyl and solvent molecule was also processed by the SHELXL (Sheldrick, 2015) [34]. Details of the X- 
ray structure determinations and refinements are provided in Table S1 (see SI).

\subsection{Polymerization studies}

Ethylene polymerization at 1 atm ethylene pressure. The polymerization at 1 atm ethylene pressure was carried out in a $100 \mathrm{~mL}$ Schlenk tube. Under an ethylene atmosphere, $\mathbf{C o 3}(3 \mu \mathrm{mol})$ was added followed by toluene $(30 \mathrm{~mL})$ and then the required amount of co-catalyst (MAO, MMAO) introduced by syringe. The solution was then stirred at $30^{\circ} \mathrm{C}$ under 1 atm of ethylene pressure. After $30 \mathrm{~min}$, the ethylene pressure was vented and solution quenched with $10 \%$ hydrochloric acid in ethanol. The polymer was washed with ethanol, dried under reduced pressure at $60{ }^{\circ} \mathrm{C}$ and then weighed.

Ethylene polymerization at 10 atm ethylene pressure. The polymerization at 10 atm ethylene pressure was carried out in a stainless steel autoclave $(0.25 \mathrm{~L})$ equipped with an ethylene pressure control system, a mechanical stirrer and a temperature controller. The autoclave was evacuated and backfilled with ethylene three times. When the required temperature was reached, the precatalyst $(3.0 \mu \mathrm{mol})$ was dissolved in toluene $(25 \mathrm{~mL})$ in a Schlenk tube and injected into the autoclave containing ethylene ( $\sim 1 \mathrm{~atm})$ followed by the addition of more toluene $(25 \mathrm{~mL})$. The required amount of co-catalyst (MAO and MMAO) and additional toluene were added successively by syringe taking the total volume of toluene to $100 \mathrm{~mL}$. The autoclave was immediately pressurized with 10 atm pressure of ethylene and the stirring commenced. After the required reaction time, the reactor was cooled with a water bath and the ethylene pressure vented. Following quenching of the reaction with $10 \%$ hydrochloric acid in ethanol, the polymer was collected and washed with ethanol and dried under reduced pressure at $60{ }^{\circ} \mathrm{C}$ and weighed.

\section{Results and Discussion}

\subsection{Synthesis and characterization}

Reaction of $\alpha, \alpha^{\prime}$-dioxo-2,3:5,6-bis(pentamethylene) with the corresponding aniline hydrochloride and cobalt chloride in acetic acid at reflux gave [2,3:5,6$\left.\left\{\mathrm{C}_{4} \mathrm{H}_{8} \mathrm{C}(\mathrm{NAr})\right\}_{2} \mathrm{C}_{5} \mathrm{HN}\right] \mathrm{CoCl}_{2}\left(\mathrm{Ar}=2-\left(\mathrm{C}_{5} \mathrm{H}_{9}\right)-6-\mathrm{MeC}_{6} \mathrm{H}_{3} \mathbf{C o 1}, 2-\left(\mathrm{C}_{6} \mathrm{H}_{11}\right)-6-\mathrm{MeC}_{6} \mathrm{H}_{3} \mathbf{C o 2}, 2-\right.$ $\left(\mathrm{C}_{8} \mathrm{H}_{15}\right)-6-\mathrm{MeC}_{6} \mathrm{H}_{3} \mathbf{C o 3}, 2-\left(\mathrm{C}_{5} \mathrm{H}_{9}\right)-4,6-\mathrm{Me}_{2} \mathrm{C}_{6} \mathrm{H}_{2}$ Co4, 2- $\left(\mathrm{C}_{6} \mathrm{H}_{11}\right)-4,6-\mathrm{Me}_{2} \mathrm{C}_{6} \mathrm{H}_{2}$ Co5, 2- $\left(\mathrm{C}_{8} \mathrm{H}_{15}\right)-$ 
4,6- $\mathrm{Me}_{2} \mathrm{C}_{6} \mathrm{H}_{2}$ Co6] in good yield (Scheme 1). Such a one-pot methodology was deemed necessary as attempts to form the free bis(imino)pyridine proved unsuccessful [16,18,27,35]. Complexes Co1 - Co6 were characterized by FTIR spectroscopy, elemental analysis and, in the case of Co1, by single crystal X-ray diffraction.

\section{$<$ Scheme 1>}

Crystals of Co1 suitable for the X-ray determination were grown by slow diffusion of hexane into a dichloromethane solution of the corresponding complex. A view of the structure is shown in Figure 1; selected bond lengths and angles are listed in the caption. The structure consists of a single cobalt center surrounded by three nitrogen atoms belonging to the tridentate ligand and two chlorides $(\mathrm{Cl} 2)$ to form a geometry that can be best described as square-based pyramidal. Specifically, C11 occupies the apical position while the basal plane is filled by $\mathrm{N}(1), \mathrm{N}(2), \mathrm{N}(3)$ and $\mathrm{Cl} 2$ with the Co atom sitting 0.514 $\AA$ above this plane; structurally related analogues have been reported $[5,16-18,27]$. The two five-membered chelate rings incorporating the tridentate ligand show some deviation from planarity which is best highlighted by the N3-C2-C1-Co1 and N1-C15-C14-N2 torsion angles of $7.37^{\circ}$ and $-6.76^{\circ}$, respectively. As is common to many bis(imino)pyridine-cobalt(II) complexes, the central Co- $\mathrm{N}_{\text {pyridine }}$ bond length [2.087(4) $\AA$ ] is shorter than the exterior Co-Nimine bond lengths $[2.169(5) \AA$ and 2.174(4) $\AA][18,25]$. Within the saturated sections of the fused sevenmembered rings (C3-C4-C5-C6 and $\mathrm{C} 10-\mathrm{C} 11-\mathrm{C} 12-\mathrm{C} 13)$, single bond character is apparent with bond distances ranging from $1.496(8)$ to $1.545(12) \AA$, while the corresponding bond angles exhibit $\mathrm{sp}^{3}$-hybridization [25]. The sterically bulky ortho-cyclopentyl substituents adopt envelope conformations which results in some tilting of the $\mathrm{N}$-aryl groups with respect to the neighboring imine vectors (dihedral angles $=69.55^{\circ}$ and $83.57^{\circ}$ ). The $\mathrm{C} 2-\mathrm{N} 3$ and C14-N2 bond lengths $[1.282(7) \AA$ and 1.291(8) $\AA]$ are consistent with $\mathrm{C}=\mathrm{N}$ double-bond character. There are no intermolecular contacts of note.

$<$ Figure 1 $>$

In the IR spectra of $\mathbf{C o 1}$ - Co6 strong peaks around $1600 \mathrm{~cm}^{-1}$ are evident which can 
be attributed to the $\mathrm{C}=\mathrm{N}$ stretching vibrations belonging to the coordinated imines $[16,18$, 27]. Furthermore, the microanalytical data for the complexes were in full agreement with elemental compositions of general formula $\mathrm{LCoCl}_{2}$.

\subsection{Catalyst evaluation for ethylene polymerization}

Complexes Co1 - Co6, have all been systematically investigated as precatalysts for ethylene polymerization using either methylaluminoxane (MAO) or modified methylaluminoxane (MMAO) as co-catalyst $[16,18,25-27,36]$. For each aluminoxane, $\mathbf{C o 3}$ was selected as the test precatalyst and variations of $\mathrm{Al} / \mathrm{Co}$ molar ratio, reaction temperature and run time were all investigated as part of the catalyst optimization; the results are compiled in Tables 1 and 2. In general, the polyethylenes were characterized by gel permeation chromatography (GPC) and different scanning calorimetry (DSC) as well as by high temperature NMR spectroscopy.

\section{Optimization of reaction conditions using Co3/MMAO}

Firstly, the effects of temperature on the performance of $\mathbf{C o 3} / \mathrm{MMAO}$ were investigated over the range 20 to $60^{\circ} \mathrm{C}$ with the $\mathrm{Al} / \mathrm{Co}$ molar ratio maintained at 2000 and the pressure of ethylene at ten atmospheres (Table 1). The highest activity of $1.91 \times 10^{6} \mathrm{~g} \mathrm{PE} \mathrm{mol}^{-1}(\mathrm{Co}) \mathrm{h}^{-1}$ was obtained at $20^{\circ} \mathrm{C}$ (entry 1, Table 1), above which it sharply decreased reaching a minimum of $0.27 \times 10^{6} \mathrm{~g}$ $\mathrm{PE} \mathrm{mol}{ }^{-1}(\mathrm{Co}) \mathrm{h}^{-1}$ at $60{ }^{\circ} \mathrm{C}$ (entry 5, Table 1). The molecular weights of the corresponding polymers followed a similar downward trend with increasing temperature (Fig. 2a), a finding that can be attributed to faster chain termination at higher temperature.

Secondly, with the temperature fixed at $20^{\circ} \mathrm{C}$, the $\mathrm{Al} / \mathrm{Co}$ molar ratio was systematically varied between 1000 and 3000 with the maximum activity reached with 2000 molar equivalents (entry 1, Table 1). Between 1000 and 2250, the $M_{\mathrm{w}}$ 's of the polyethylenes gradually decreased from 61.3 to $42.6 \mathrm{~kg} \mathrm{~mol}^{-1}$ (Fig. 2b), a result that can be likely ascribed to increased chain transfer occurring from cobalt to aluminum as a consequence of the larger amounts of alkyl aluminum reagent employed [5, 8, 37]. Interestingly, with the molar ratios between 2500 and 3000, a dramatic increase in molecular weight was observed with values reaching as high as $53.8 \mathrm{~kg} \mathrm{~mol}^{-}$ ${ }^{1}$ with 3000 equivalents of MMAO. It would seem plausible that the formation of a new active 
species has occurred within this molar ratio window, a similar observation has been noted elsewhere [26].

Thirdly, to determine the catalyst lifetime, the polymerization runs were performed over different intervals with the highest activity of $2.00 \times 10^{6} \mathrm{~g} \mathrm{PE} \mathrm{mol}^{-1}(\mathrm{Co}) \mathrm{h}^{-1}$ observed after 15 minutes (entry 12, Table 1). When the run time was extended to 60 minutes (entry 14, Table 1), only ca. $50 \%$ loss of activity was observed, highlighting the stability and slow deactivation of this catalyst. In terms of molecular weight, longer reactions were accompanied by an increase in $M_{\mathrm{w}}$ from 43.5 to $52.4 \mathrm{~kg} \mathrm{~mol}^{-1}$ (Fig. 2c).

The effect of ethylene pressure was also found to be significant with the activity at one atmosphere being around one tenth of that observed at 10 atmospheres (entries 1 and 15, Table 1). On the other hand, the molecular weight remained essentially invariant. These results are consistent with both chain propagation and chain termination increasing equally with ethylene pressure $[36,38]$.

$<$ Table 1 $>$

$<$ Figure $2>$

\section{Optimization of reaction conditions using Co3/MAO}

To complement the study performed with MMAO, we also examined the performance of $\mathbf{C o 3}$ using MAO as the co-catalyst. As before, the first stage of catalytic optimization focused on the effect of temperature (entries $1-5$, Table 2$)$. The maximum activity was achieved at $30{ }^{\circ} \mathrm{C}(1.21$ $\left.\times 10^{6} \mathrm{~g} \mathrm{PE} \mathrm{mol}^{-1}(\mathrm{Co}) \mathrm{h}^{-1}\right)$, above which the activity steadily lowered until at $60^{\circ} \mathrm{C}$ the activity had dropped almost threefold. At the same time, the molecular weight decreased significantly with increasing temperature from 53.1 to $18.2 \mathrm{~kg} \mathrm{~mol}^{-1}$ (see Fig. 3a).

With the temperature maintained at $30^{\circ} \mathrm{C}$, the effect of varying the $\mathrm{Al} / \mathrm{Co}$ molar ratio from 1000 to 3000 was studied. A peak in activity of $1.35 \times 10^{6} \mathrm{~g} \mathrm{PE} \mathrm{mol}^{-1}(\mathrm{Co}) \mathrm{h}^{-1}$ was identified with an Al/Co ratio of 1500 (entries 6 - 11, Table 2). Unlike with MMAO, no anomalous behavior was observed with the molecular weight steadily dropping as the ratio was increased from 1000 to 3000 in agreement with increased chain transfer from the active cobalt species to aluminum (see Fig. 3b) [8, 18, 27, 39-40]. With respect to run time, the performance of $\mathbf{C o 3} / \mathrm{MAO}$ mirrored 
Co3/MMAO, with the activity gradually decreasing over time while the molecular weight increased (see Fig. 3c).

As noted earlier, the catalyst activity of $\mathbf{C o 3} / \mathrm{MMAO}$ was also found to drop markedly on reducing the ethylene pressure for 10 to 1 atmosphere, while the molecular weight of the material remained similar at either pressure. As a general feature common to both co-catalysts, the range in molecular weight and molecular weight distributions are comparable, while the activity using MAO is slightly lower, a finding that contrasts with that reported with structurally related cobalt analogs [18].

$<$ Table 2>

$<$ Figure 3 $>$

\section{Structural effects of precatalyst on polymerization using MMAO or MAO}

To investigate the influence of structural variations of the precatalyst on catalyst performance and polymer properties, all six cobalt complexes, Co1 - Co6, were systematically studied. For the sake of comparison, the previously reported $\left[2,3: 5,6-\left\{\mathrm{C}_{4} \mathrm{H}_{8} \mathrm{C}(\mathrm{N}(2,6-\right.\right.$ $\left.\left.\left.\left.\mathrm{Me}_{2} \mathrm{C}_{6} \mathrm{H}_{3}\right)\right)\right\}_{2} \mathrm{C}_{5} \mathrm{HN}\right] \mathrm{CoCl}_{2}(\mathbf{C o m e 2 P h}$, Scheme 1) was also included in the evaluation [18]. Firstly, using the optimized conditions established for $\mathbf{C o 3} / \mathrm{MMAO}\left[\mathrm{Al} / \mathrm{Co}=2000\right.$, temperature $=20^{\circ} \mathrm{C}$, run time $=30$ minutes], $\mathbf{C o 1}-\mathbf{C o 6}$, on activation with MMAO, exhibited good activities in the range $1.31-2.22 \times 10^{6} \mathrm{~g} \mathrm{PE} \mathrm{mol}^{-1}(\mathrm{Co}) \mathrm{h}^{-1}$ that fall in the order: $\mathbf{C o 5}$ (2-cyclohexyl-4,6-methyl) $\sim \operatorname{Co2}$ (2-cyclohexyl-6-methyl) > Co1 (2-cyclopentyl-6-methyl) > Co3 (2-cyclooctyl-6-methyl) > Co4 (2-cyclopentyl-4,6-methyl) > Co6 (2-cyclooctyl-4,6-methyl). With respect to the particular para-R group, Co2 (2-cyclohexyl-6-methyl) > Co1 (2-cyclopentyl-6-methyl) > Co3 (2cyclooctyl-6-methyl) for $\mathrm{R}^{2}=\mathrm{H}$ and $\mathrm{Co5}$ (2-cyclohexyl-4,6-methyl) > Co4 (2-cyclopentyl-4,6methyl) > Co6 (2-cyclooctyl-4,6-methyl) for $\mathrm{R}^{2}=$ Me. Several points emerge from examination of these findings. Firstly, the type of cycloalkyl group positioned at the ortho-position of the Naryl group affects catalytic activity with the cyclohexyl systems giving the highest activities (Co5, Co2), while for a specific para-R group cyclooctyl shows the lowest $(\mathbf{C o 3}, \mathbf{C o 6})$. Secondly, the nature of the 4-R group is also influential on catalytic activity with the 4-H derivative more active than its 4-Me analog for the pairs $\mathrm{Co6} / \mathrm{Co3}$ and $\mathrm{Co4} / \mathrm{Co1}$, though similar for $\mathrm{Co5} / \mathrm{Co2}$. To 
explain the superior performance of the cyclohexyl systems it would seem plausible that the flexibility of the cyclohexyl ring provides the most suitable protection to the metal center in the active catalyst but does not impede the approach of the ethylene monomer. With respect to the molecular weight, values in the range $33.7-55.6 \mathrm{~kg} \mathrm{~mol}^{-1}$ were observed with the most bulky cyclooctyl-containing $\mathbf{C o 3}$ and $\mathbf{C o 6}$ affording polymer at the top end and cyclohexyl $\mathbf{C o 5}$ and Co2 the bottom, trends that are clearly the inverse of that found for activity. In comparison with CoMe2Ph/MMAO, the ortho-cycloalkyl systems in general exhibited an order of magnitude higher molecular weight, although the catalytic activity is slightly lower (Fig. 4 left) [18].

With MAO as co-catalyst similar trends in activity and molecular weight are observed with the cyclohexyl systems $(\mathbf{C o 5}, \mathbf{C o 2})$ again showing the highest activity and the lowest molecular weight. By contrast, the cyclooctyl systems $(\mathbf{C o 6}, \mathbf{C o 3})$ give the lowest activity but the highest molecular weight (Table 3). By comparison, the catalytic activity of CoMe2Ph/MAO is nearly twice as much as that seen for Co2, Co4 and Co5, and almost five times that for Co6. As with MMAO-promoted polymerizations, the molecular weights obtained using Co1 - Co6 (range: 29.6 - $\left.52.0 \mathrm{~kg} \mathrm{~mol}^{-1}\right)$ are all significantly higher than that seen for CoMe2Ph $\left(12.1 \mathrm{~kg} \mathrm{~mol}^{-1}\right)$ (Fig. 4 , right).

As a common feature, regardless of MMAO or MAO activation, narrow unimodal distributions of the polymers are observed (PDI range: $1.86-4.23$ ) consistent with single-sitelike active species. In addition, high melting temperatures of the polymers $\left(T_{\mathrm{m}}\right.$ values: $130-136$ ${ }^{\circ} \mathrm{C}$ ) are supportive of the polyethylenes displaying high linearity [5], while their heat of fusion data indicate exceptionally high crystallinity (average $200 \mathrm{~J} / \mathrm{g} v s 170 \mathrm{~J} / \mathrm{g}$ for commercial HDPE). Comparatively, polymers obtained using CoMe2Ph/MMAO or CoMe2Ph/MAO gave lower $T_{\mathrm{m}}$ values $\left(128.0-130.1^{\circ} \mathrm{C}\right)$ and heats of fusion data that fell at the lower end of the range.

\section{$<$ Table $3>$}

$<$ Figure 4 $>$

To provide further support for the linearity of the polymers, representative samples synthesized using $\mathbf{C o 3} / \mathrm{MAO}$ at $30{ }^{\circ} \mathrm{C}$ (entry 10, Table 3), Co3/MMAO (entry 3, Table 3) at 20 ${ }^{\circ} \mathrm{C}$ and Co2/MMAO at $20{ }^{\circ} \mathrm{C}$ (entry 2, Table 3), were characterized by ${ }^{13} \mathrm{C}$ NMR spectroscopy (recorded in 1,1,2,2-tetrachloroethane- $d_{2}$ at $135^{\circ} \mathrm{C}$ ). In each case high intensity singlets observed 
around $\delta 30.00$ (see Figs. 5, 6a and 6b) were the only signals detectable which can be assigned to the $-\left(\mathrm{CH}_{2}\right)_{\mathrm{n}}$ - repeat unit in accord with high linearity $[18,27]$. On the other hand, a sample of the polyethylene prepared using $\mathbf{C o 6} / \mathrm{MMAO}$ at $20{ }^{\circ} \mathrm{C}$ (entry 6, Table 3) revealed on close inspection of the aliphatic region additional weak peaks at $\delta 32.23,22.94$ and 14.27 (peaks 3,2, and 1 in Fig. 6) that could be attributed to $n$-propyl end-groups. Indeed, a lower molecular weight sample of polyethylene prepared using $\mathbf{C o 3} / \mathrm{MMAO}$ at $60^{\circ} \mathrm{C}$ (entry 5, in Table 1) again showed these low intensity $n$-propyl peaks (peaks 3, 2, and 1 in Fig. 7) [41]. However, examination of the downfield region in this spectrum revealed no evidence for peaks that could be assigned to unsaturated chain ends, which would suggest the absence of termination via $\beta$-H elimination and hence transfer to aluminum as the key termination pathway.

$<$ Figure 5 $>$

$<$ Figure 6>

$<$ Figure $7>$

To further explore the properties of the polyethylenes, we also conducted a series of measurements concerned with their surface properties [42, 43, 44]. In this regard the value of the water contact angle (WCA) can be informative when put alongside the value of $101.4^{\circ}$ for commercial sample of low-density polyethylene (LDPE) of high molecular weight $\left(M_{\mathrm{w}} \approx 914.7\right.$ $\left.\mathrm{kg} \mathrm{mol}^{-1}\right)$ and low $T_{\mathrm{m}}\left(107^{\circ} \mathrm{C}\right)$ [45]. For the polymer obtained at $60^{\circ} \mathrm{C}$ using $\mathbf{C o 3} / \mathrm{MMAO}$ (entry 5, Table 1), its WCA was determined as $110.3^{\circ}$, while for the polymers generated at $20^{\circ} \mathrm{C}$, using Co1/MMAO (entry 1, Table 3) and Co2/MMAO (entry 2, Table 3), the WCA's were $109.8^{\circ}$ and $111.8^{\circ}$, respectively. Generally, all the polymers studied exhibited superior hydrophobic properties when compared against the commercial sample of polyethylene.

$<$ Figure $8>$

\section{Conclusions}

A family of six cobalt(II) chloride complexes, Co1 - Co6, bound by ring-fused $\alpha, \alpha^{\prime}-$ bis(cycloarylimino)-2,3:5,6-bis-(pentamethylene)pyridines, was systematically synthesized using a one-pot approach and fully characterized. On activation with either MMAO or MAO, all these ortho-cycloalkyl-containing complexes afforded strictly linear polyethylene with high 
molecular weight and indeed around $40 \mathrm{~kg} \mathrm{~mol}^{-1}$ higher than that observed with a previously studied structural analog CoMe2Ph. In terms of catalytic activity, the cyclohexyl-substituted catalysts $(\mathbf{C o 2}, \mathbf{C o 5})$ were higher than the cyclopentyl-containing catalysts $(\mathbf{C o 1}, \mathbf{C o 4})$ which were in-turn higher than the cyclooctyl-substituted ones $(\mathbf{C o 3}, \mathbf{C o 6})$. In general, the MMAOpromoted polymerizations showed higher activities than with their MAO counterparts.

Declarations of interest: none

\section{Acknowledgements}

This work was supported by the National Natural Science Foundation of China (Nos. U1362204 and 21611130026). GAS thanks the Chinese Academy of Sciences for a President's International Fellowship for Visiting Scientists.

\section{References}

[1] V.C. Gibson, S.K. Spitzmesser, Advances in non-metallocene olefin polymerization catalysis, Chem. Rev. 103 (2003) 283-316.

[2] G.J.P. Britovsek, V.C. Gibson, D.F. Wass, The search for new-generation olefin polymerization catalysts: Life beyond metallocenes, Angew. Chem. Int. Ed. 38 (1999) 428-447. [3] S.D. Ittel, L.K. Johnson, M. Brookhart, Late-metal catalysts for ethylene homo- and copolymerization, Chem. Rev. (Washington, DC, U. S.) 100 (2000) 1169-1203.

[4] Z. Wang, G.A. Solan, W. Zhang, W.-H. Sun, Carbocyclic-fused $N, N, N$-pincer ligands as ring-strain adjustable supports for iron and cobalt catalysts in ethylene oligo-/polymerization, Coord. Chem. Rev. 363 (2018) 92-108.

[5] B.L. Small, M. Brookhart, A.M.A. Bennett, Highly active iron and cobalt catalysts for the polymerization of ethylene, J. Am. Chem. Soc. 120 (1998) 4049-4050.

[6] G.J.P. Britovsek, V.C. Gibson, S.J. McTavish, G.A. Solan, A.J.P. White, D.J. Williams, G.J.P. Britovsek, B.S. Kimberley, P.J. Maddox, Novel olefin polymerization catalysts based on iron and cobalt, Chem. Commun. (1998) 849-850.

[7] B.L. Small, M. Brookhart, Iron-based catalysts with exceptionally high activities and selectivities for oligomerization of ethylene to linear $\alpha$-olefins, J. Am. Chem. Soc. 120 (1998) 7143-7144.

[8] G.J.P. Britovsek, M. Bruce, V.C. Gibson, B.S. Kimberley, P.J. Maddox, S. Mastroianni, S.J. McTavish, C. Redshaw, G.A. Solan, S. Strömberg, A.J.P. White, D.J. Williams, Iron and cobalt ethylene polymerization catalysts bearing 2,6-bis(imino)pyridyl ligands: Synthesis, structures, and polymerization studies, J. Am. Chem. Soc. 121 (1999) 8728-8740.

[9] C. Bianchini, G. Giambastiani, I.G. Rios, G. Mantovani, A. Meli, A.M. Segarra, Ethylene oligomerization, homopolymerization and copolymerization by iron and cobalt catalysts with 2,6-(bis-organylimino)pyridyl ligands, Coord. Chem. Rev. 250 (2006) 1391-1418.

[10] G.J.P. Britovsek, S. Mastroianni, G.A. Solan, S.P.D. Baugh, C. Redshaw, V.C. Gibson, A.J.P. White, D.J. Williams, M.R.J. Elsegood, Oligomerisation of ethylene by 
bis(imino)pyridyliron and -cobalt complexes, Chem. Eur. J. 6 (2000) 2221-2231.

[11] V.C. Gibson, C. Redshaw, G.A. Solan, Bis(imino)pyridines: Surprisingly reactive ligands and a gateway to new families of catalysts, Chem. Rev. 107 (2007) 1745-1776.

[12] G.J.P. Britovsek, V.C. Gibson, B.S. Kimberley, S. Mastroianni, C. Redshaw, G.A. Solan, A.J.P. White, D.J. Williams, Bis(imino)pyridyl iron and cobalt complexes: The effect of nitrogen substituents on ethylene oligomerisation and polymerisation, J. Chem. Soc., Dalton Trans. (2001) 1639-1644.

[13] G.J.P. Britovsek, V.C. Gibson, O.D. Hoarau, S.K. Spitzmesser, A.J.P. White, D.J. Williams, Iron and cobalt ethylene polymerization catalysts: Variations on the central donor, Inorg. Chem. 42 (2003) 3454-3465.

[14] L. Guo, H. Gao, L. Zhang, F. Zhu, Q. Wu, An unsymmetrical iron(II) bis(imino)pyridyl catalyst for ethylene polymerization: Effect of a bulky ortho substituent on the thermostability and molecular weight of polyethylene, Organometallics 29 (2010) 2118-2125.

[15] Z. Flisak, W.-H. Sun, Progression of diiminopyridines: From single application to catalytic versatility, ACS Catal. 5 (2015) 4713-4724.

[16] F. Huang, W. Zhang, E. Yue, T. Liang, X. Hu, W.H. Sun, Controlling the molecular weights of polyethylene waxes using the highly active precatalysts of 2-(1-aryliminoethyl)-9arylimino-5,6,7,8-tetrahydrocycloheptapyridylcobalt chlorides: Synthesis, characterization, and catalytic behavior, Dalton Trans. 45 (2016) 657-666.

[17] F. Huang, W. Zhang, Y. Sun, X. Hu, G.A. Solan, W.-H. Sun, Thermally stable and highly active cobalt precatalysts for vinyl-polyethylenes with narrow polydispersities: Integrating fused-ring and imino-carbon protection into ligand design, New J. Chem. 40 (2016) 8012-8023. [18] S. Du, W. Zhang, E. Yue, F. Huang, T. Liang, W.-H. Sun, $\alpha, \alpha^{\prime}$-bis(arylimino)-2,3:5,6bis(pentamethylene)pyridylcobalt chlorides: Synthesis, characterization, and ethylene polymerization behavior, Eur. J. Inorg. Chem. 2016 (2016) 1748-1755.

[19] F. He, W. Zhao, X. Cao, T. Liang, C. Redshaw, W.-H. Sun, 2-[1-(2,6-dibenzhydryl-4chlorophenylimino)ethyl]-6-[1-aryliminoethyl]pyridyl cobalt dichlorides: Synthesis, characterization and ethylene polymerization behavior, J. Organomet. Chem. 713 (2012) 209216.

[20] S. Jie, S. Zhang, W.-H. Sun, X. Kuang, T. Liu, J. Guo, Iron(II) complexes ligated by 2imino-1,10-phenanthrolines: Preparation and catalytic behavior toward ethylene oligomerization, J. Mol. Catal. A: Chem. 269 (2007) 85-96.

[21] J.D.A. Pelletier, Y.D.M. Champouret, J. Cadarso, L. Clowes, M. Gañete, K. Singh, V. Thanarajasingham, G.A. Solan, Electronically variable imino-phenanthrolinyl-cobalt complexes; synthesis, structures and ethylene oligomerisation studies, J. Organomet. Chem. 691 (2006) 4114-4123.

[22] W.-H. Sun, P. Hao, S. Zhang, Q. Shi, W. Zuo, X. Tang, Iron(II) and cobalt(II) 2(benzimidazolyl)-6-(1-(arylimino)ethyl)pyridyl complexes as catalysts for ethylene oligomerization and polymerization, Organometallics 26 (2007) 2720-2734.

[23] K. Wang, P. Hao, D. Zhang, W.-H. Sun, Tridentate $\mathrm{N}^{\wedge} \mathrm{N}^{\wedge} \mathrm{N}$ iron(II) and cobalt(II) complexes of ion-paired structures: Synthesis, characterization and magnetism, J. Mol. Struct. 890 (2008) 95-100.

[24] S. Zhang, W.-H. Sun, T. Xiao, X. Hao, Ferrous and cobaltous chlorides bearing 2,8- 
bis(imino)quinolines: Highly active catalysts for ethylene polymerization at high temperature, Organometallics 29 (2010) 1168-1173.

[25] V.K. Appukuttan, Y. Liu, B.C. Son, C.-S. Ha, H. Suh, I. Kim, Iron and cobalt complexes of 2,3,7,8-tetrahydroacridine-4,5 $(1 H, 6 H)$-diimine sterically modulated by substituted aryl rings for the selective oligomerization to polymerization of ethylene, Organometallics 30 (2011) 2285-2294.

[26] W.-H. Sun, S. Kong, W. Chai, T. Shiono, C. Redshaw, X. Hu, C. Guo, X. Hao, 2-(1(arylimino)ethyl)-8-arylimino-5,6,7-trihydroquinolylcobalt dichloride: Synthesis and polyethylene wax formation, Appl. Catal., Part A: Gen. 447-448 (2012) 67-73.

[27] Z. Wang, G.A. Solan, Q. Mahmood, Q. Liu, Y. Ma, X. Hao, W.-H. Sun, Bis(imino)pyridines incorporating doubly fused eight-membered rings as conformationally flexible supports for cobalt ethylene polymerization catalysts, Organometallics 37 (2018) 380389.

[28] Z. Sun, E. Yue, M. Qu, I.V. Oleynik, I.I. Oleynik, K. Li, T. Liang, W. Zhang, W.-H. Sun, 8-(2-cycloalkylphenylimino)-5,6,7-trihydro-quinolylnickel halides: Polymerizing ethylene to highly branched and lower molecular weight polyethylenes, Inorg. Chem. Front. 2 (2015) 223227.

[29] S.S. Ivanchev, G.A. Tolstikov, V.K. Badaev, I.I. Oleinik, N.I. Ivancheva, D.G. Rogozin, I.V. Oleinik, S.V. Myakin, New bis(arylimino)pyridyl complexes as components of catalysts for ethylene polymerization, Kinetics and Catalysis 45 (2004) 176-182.

[30] H. Suo, I.V. Oleynik, C. Huang, I.I. Oleynik, G.A. Solan, Y. Ma, T. Liang, W.-H. Sun, Ortho-cycloalkyl substituted N,N' -diaryliminoacenaphthene-Ni(II) catalysts for polyethylene elastomers; exploring ring size and temperature effects, Dalton Trans. 46 (2017) 15684-15697. [31] Z. Sun, F. Huang, M. Qu, E. Yue, I.V. Oleynik, I.I. Oleynik, Y. Zeng, T. Liang, K. Li, W. Zhang, W.-H. Sun, Targeting polyethylene waxes: 9-(2-cycloalkylphenylimino)-5,6,7,8tetrahydrocycloheptapyridylnickel halides and their use as catalysts for ethylene polymerization, RSC Adv. 5 (2015) 77913-77921.

[32] I.I. Oleinik, I.V. Oleinik, I.B. Abdrakhmanov, S.S. Ivanchev, G.A. Tolstikov, Design of arylimine postmetallocene catalytic systems for olefin polymerization: I. Synthesis of substituted 2-cycloalkyl- and 2,6-dicycloalkylanilines, Russ. J. Gen. Chem. 74 (2004) 14231427.

[33] G.M. Sheldrick, SHELXT - Integrated space-group and crystalstructure determination, Acta Cryst. A71 (2015) 3-8.

[34] G.M. Sheldrick, Crystal structure refinement with SHELXL, Acta Cryst. C71 (2015) 3-8.

[35] A.M. Archer, M.W. Bouwkamp, M.P. Cortez, E. Lobkovsky, P.J. Chirik, Arene coordination in bis(imino)pyridine iron complexes: Identification of catalyst deactivation pathways in iron-catalyzed hydrogenation and hydrosilation, Organometallics 25 (2006) 42694278.

[36] Y. Chen, R. Chen, C. Qian, X. Dong, J. Sun, Halogen-substituted 2,6-bis(imino)pyridyl iron and cobalt complexes: Highly active catalysts for polymerization and oligomerization of ethylene, Organometallics 22 (2003) 4312-4321.

[37] A.K. Tomov, V.C. Gibson, G.J.P. Britovsek, R.J. Long, M. van Meurs, D.J. Jones, K.P. Tellmann, J.J. Chirinos, Distinguishing chain growth mechanisms in metal-catalyzed olefin 
oligomerization and polymerization systems: $\mathrm{C}_{2} \mathrm{H}_{4} / \mathrm{C}_{2} \mathrm{D}_{4}$ co-oligomerization/polymerization experiments using chromium, iron, and cobalt catalysts, Organometallics 28 (2009) 7033-7040. [38] D.P. Gates, S.A. Svejda, E. Oñate, C.M. Killian, L.K. Johnson, P.S. White, M. Brookhart, Synthesis of branched polyethylene using ( $\alpha$-diimine)nickel(II) catalysts: Influence of temperature, ethylene pressure, and ligand structure on polymer properties, Macromolecules 33 (2000) 2320-2334.

[39] C. Huang, S. Du, G.A. Solan, Y. Sun, W.-H. Sun, From polyethylene waxes to HDPE using an $\alpha, \alpha^{\prime}$-bis(arylimino)-2,3:5,6-bis(pentamethylene)pyridyl-chromium(III) chloride precatalyst in ethylene polymerisation, Dalton Trans. 46 (2017) 6948-6957.

[40] D.J. Jones, V.C. Gibson, S.M. Green, P.J. Maddox, A.J.P. White, D.J. Williams, Discovery and optimization of new chromium catalysts for ethylene oligomerization and polymerization aided by high-throughput screening, J. Am. Chem. Soc. 127 (2005) 1103711046.

[41] N.V. Semikolenova, W.-H. Sun, I.E. Soshnikov, M.A. Matsko, O.V. Kolesova, V.A. Zakharov, K.P. Bryliakov, Origin of "multisite-like" ethylene polymerization behavior of the single-site nonsymmetrical bis(imino)pyridine iron(II) complex in the presence of modified methylaluminoxane, ACS Catal. 7 (2017) 2868-2877.

[42] C.W. Extrand, Contact angles and their hysteresis as a measure of liquid-solid adhesion, Langmuir 20 (2004) 4017-4021.

[43] Q. Liu, H. Zou, Y. Shao, Z. Wang, Stable superhydrophobic surface based on low-density polyethylene/ethylene-propylene-diene terpolymer thermoplastic vulcanizate. J. Appl. Polym. Sci. 135 (2018) 46241-46246.

[44] D.K. Owens, R.C. Wendt, Estimation of the surface free energy of polymers, J. Appl. Polym. Sci. 13 (1969) 1741-1747.

[45] X. Lu, C. Zhang, Y. Han, Low-density polyethylene superhydrophobic surface by control of its crystallization behavior, Macromol. Rapid Commun. 25 (2004) 1606-1610.

\section{Captions of Chart, Scheme, Figures and Tables}

Chart 1 Fused ligand frameworks derived from parent bis(imino)pyridine $\mathbf{A}$

Scheme 1 Synthesis of Co1 - Co6 and a representation of CoMe2Ph

Figure 1 OLEX2 representation of Co1; the thermal ellipsoids are shown at the $30 \%$ probability level and all hydrogen atoms have been omitted for clarity.

Figure 2 Molecular weight $\left(M_{\mathrm{w}}\right)$ and PDI versus a) run temperature b) Al/Co molar ratio and c) run time using $\mathbf{C o 3} / \mathrm{MMAO}$.

Figure 3 Molecular weight $\left(M_{\mathrm{w}}\right)$ and PDI versus a) run temperature b) Al/Co molar ratio and c) run time using Co3/MAO.

Figure 4 Comparison of the catalytic activities and molecular weight of the polyethylenes generated using Co1 - Co6 and CoMe2Ph with (i) MMAO (left) and (ii) MAO (right) as co- 
catalysts.

Figure $5{ }^{13} \mathrm{C}$ NMR spectrum of the polyethylene obtained using $\mathbf{C o 3} / \mathrm{MAO}$ at $30{ }^{\circ} \mathrm{C}$ (entry 2, in Table 3); recorded in 1,1,2,2-tetrachloroethane- $d_{2}$ at $135^{\circ} \mathrm{C}(\delta \mathrm{C} 73.8)$.

Figure $6{ }^{13} \mathrm{C}$ NMR spectra of the polyethylene obtained using a) Co3/MMAO b) Co2/MMAO and c) Co6/MMAO after 30 minutes at $20^{\circ} \mathrm{C}$ (entries 3, 2, and 6, Table 4); all spectra recorded in 1,1,2,2-tetrachloroethane- $d_{2}$ at $135^{\circ} \mathrm{C}(\delta \mathrm{C} 73.8)$.

Figure $7{ }^{13} \mathrm{C}$ NMR spectrum of the polyethylene obtained with $\mathrm{Co3} / \mathrm{MMAO}$ at $60{ }^{\circ} \mathrm{C}$ (entry 5 , in Table 2); recorded in 1,1,2,2-tetrachloroethane- $d_{2}$ at $135^{\circ} \mathrm{C}(\delta \mathrm{C} 73.8)$.

Figure 8 The water contact angles for the polyethylenes obtained using a) Co3/MMAO at 60 ${ }^{\circ} \mathrm{C}$, b) Co1/MMAO at $20^{\circ} \mathrm{C}$ and c) $\mathbf{C o 2} / \mathrm{MMAO}$ at $20^{\circ} \mathrm{C}$

Table 1 Ethylene polymerization by $\mathbf{C o 3} / \mathrm{MMAO}$

Table 2 Ethylene polymerization by $\mathbf{C o 3} / \mathrm{MAO}$

Table 3 Ethylene polymerization using Co1 - Co6 and CoMe2Ph using either MMAO or MAO

\section{Supporting Information}

Table S1 Crystal data and structure refinement for Co1

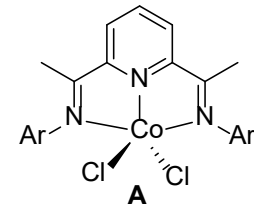

$M_{\mathrm{w}}: 1.6-257 \mathrm{~kg} / \mathrm{mol}$ PDI: $2.6-144.5$

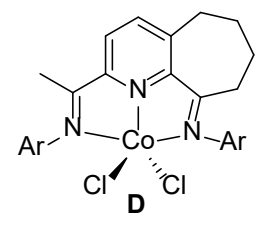

$M_{\mathrm{w}}: 2.3-7.1 \mathrm{~kg} / \mathrm{mol}$ PDI: 1.6 - 4.0

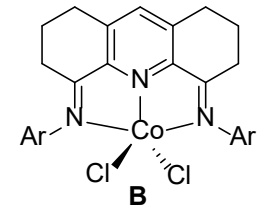

$M_{\mathrm{w}}: 0.6-5.2 \mathrm{~kg} / \mathrm{mol}$ PDI: 1.4 - 6.6

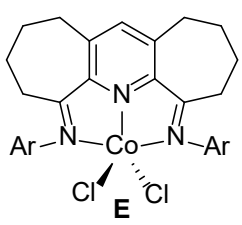

$M_{\mathrm{w}}: 4.1-12.1 \mathrm{~kg} / \mathrm{mol}$ PDI: 2.1 - 2.8

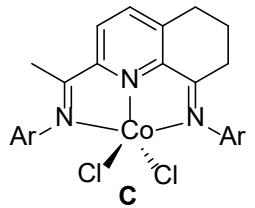

$M_{\mathrm{w}}: 0.8-1.2 \mathrm{~kg} / \mathrm{mol}$ PDI: $1.4-1.9$

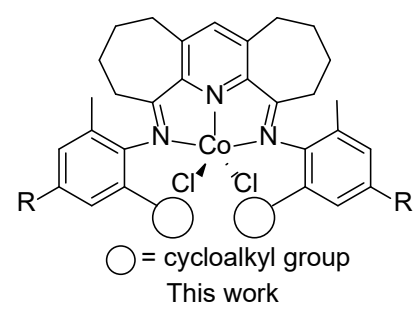

Chart 1 Fused ligand frameworks derived from parent bis(imino)pyridine $\mathbf{A}$ 


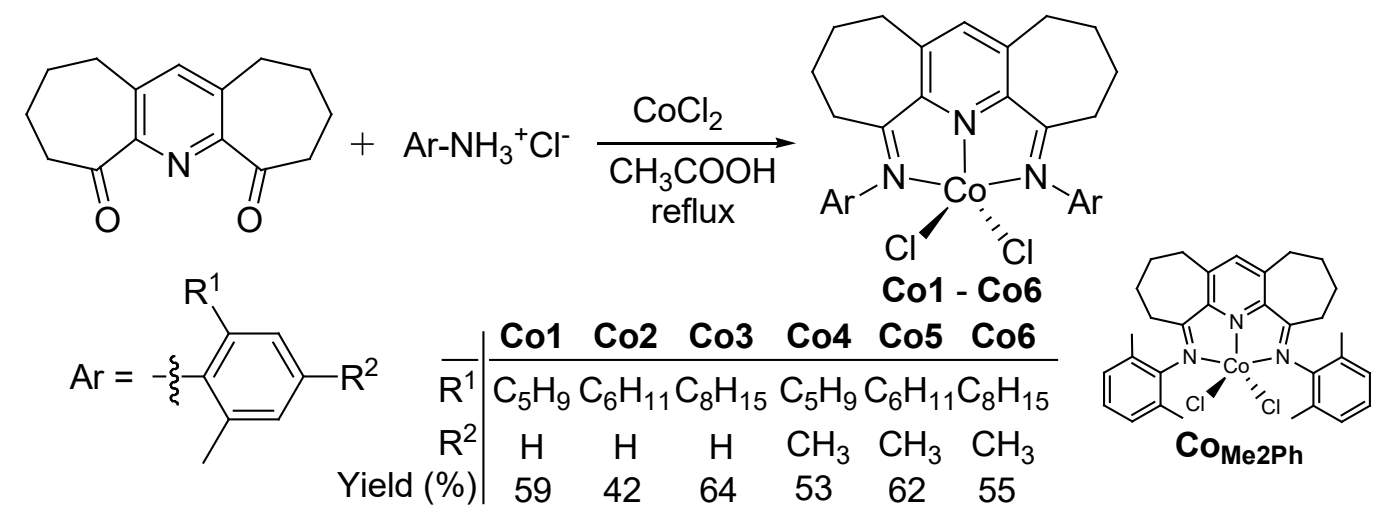

Scheme 1 Synthesis of Co1 - Co6 and a representation of CoMe2Ph [18]

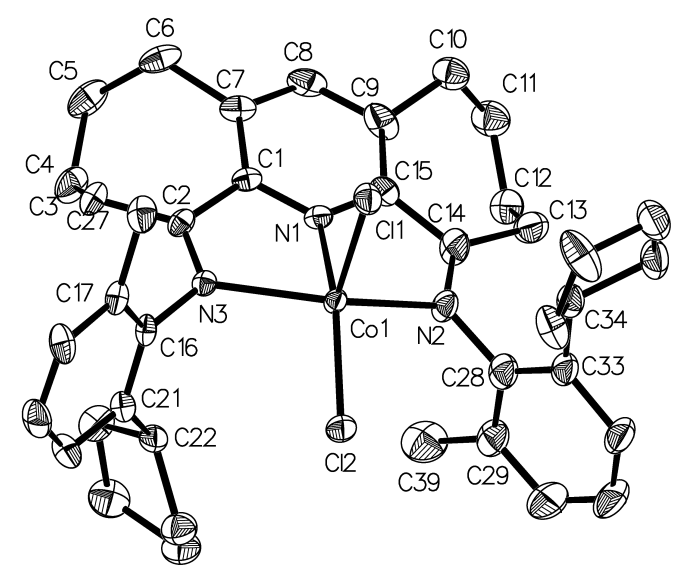

Figure 1 OLEX2 representation of Co1; the thermal ellipsoids are shown at the $30 \%$ probability level and all hydrogen atoms have been omitted for clarity. Selected bond lengths $[\AA]$ and angles $\left[^{\circ}\right]$ : Co1-N1 2.087(4), Co1-N2 2.169(5), Co1-N3 2.174(4), C2-N3 1.282(7), C14-N2 1.291(8), N1-Co1-N2 73.72(18), N1-Co1-N3 74.20(17), N2-Co1-N3 141.51(18), C11-Co1-C12 115.03(7), C14-C13-C12 110.8(9), C13C12-C11 113.5(8), C12-C11-C10 116.4(9), C11-C10-C9 109.5(9).

a)

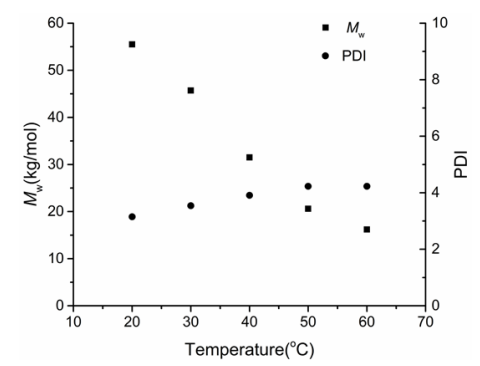

b)

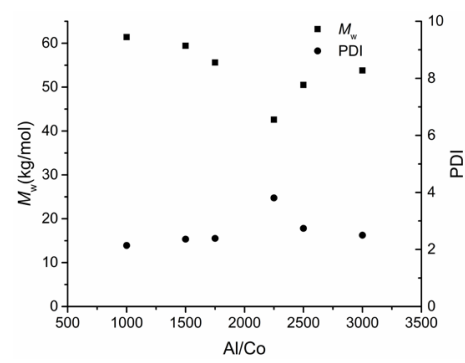

c)

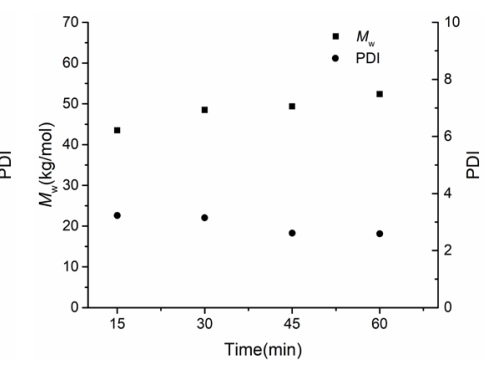

Figure 2 Molecular weight $\left(M_{\mathrm{w}}\right)$ and PDI versus a) run temperature b) $\mathrm{Al} / \mathrm{Co}$ molar ratio and c) run time using Co3/MMAO. 
a)

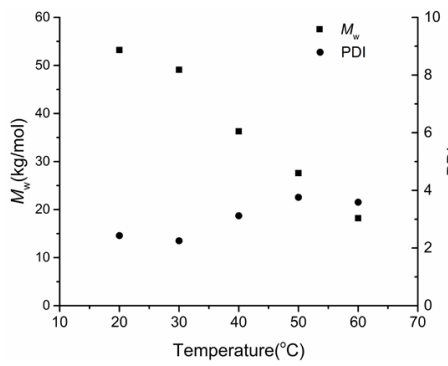

b)

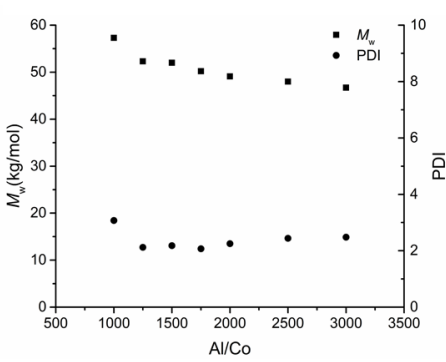

c)

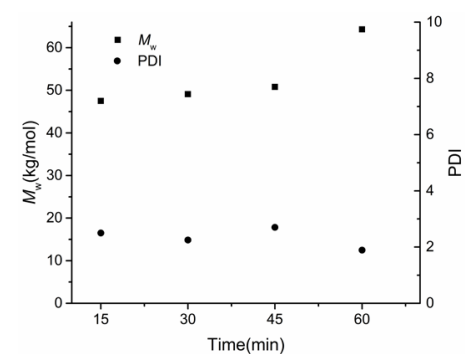

Figure 3 Molecular weight $\left(M_{\mathrm{w}}\right)$ and PDI versus a) run temperature b) Al/Co molar ratio and c) run time using Co3/MAO.
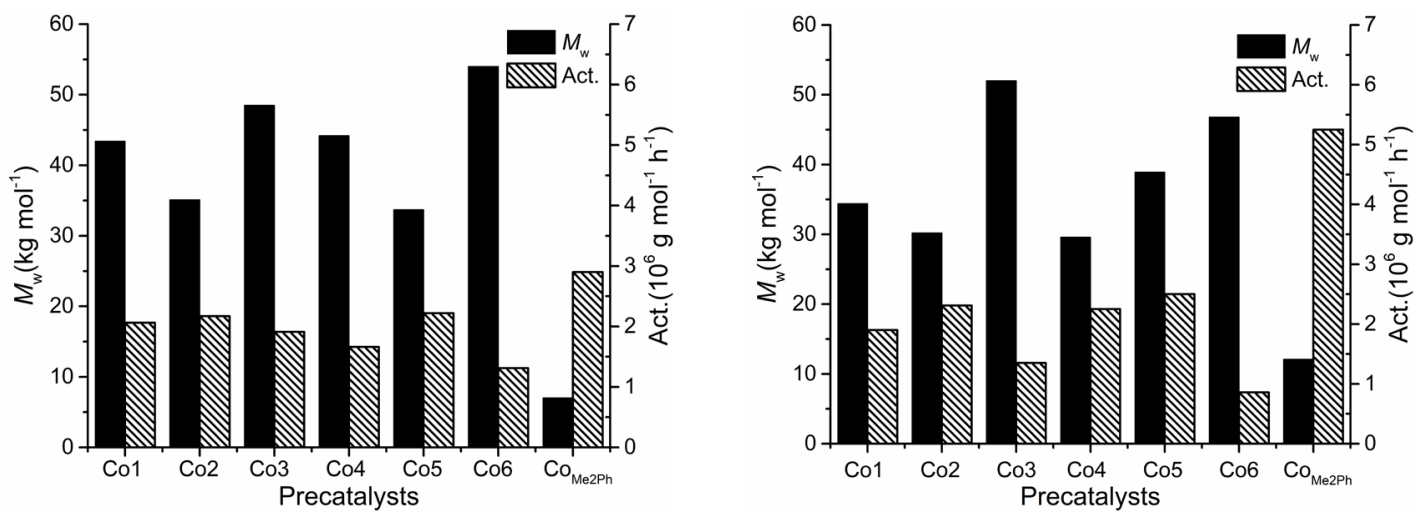

Figure 4 Comparison of the catalytic activities and molecular weight of the polyethylenes generated using Co1 - Co6 and Co $\mathbf{M}_{\text {Me2ph }}$ with (i) MMAO (left) and (ii) MAO (right) as co-catalysts.

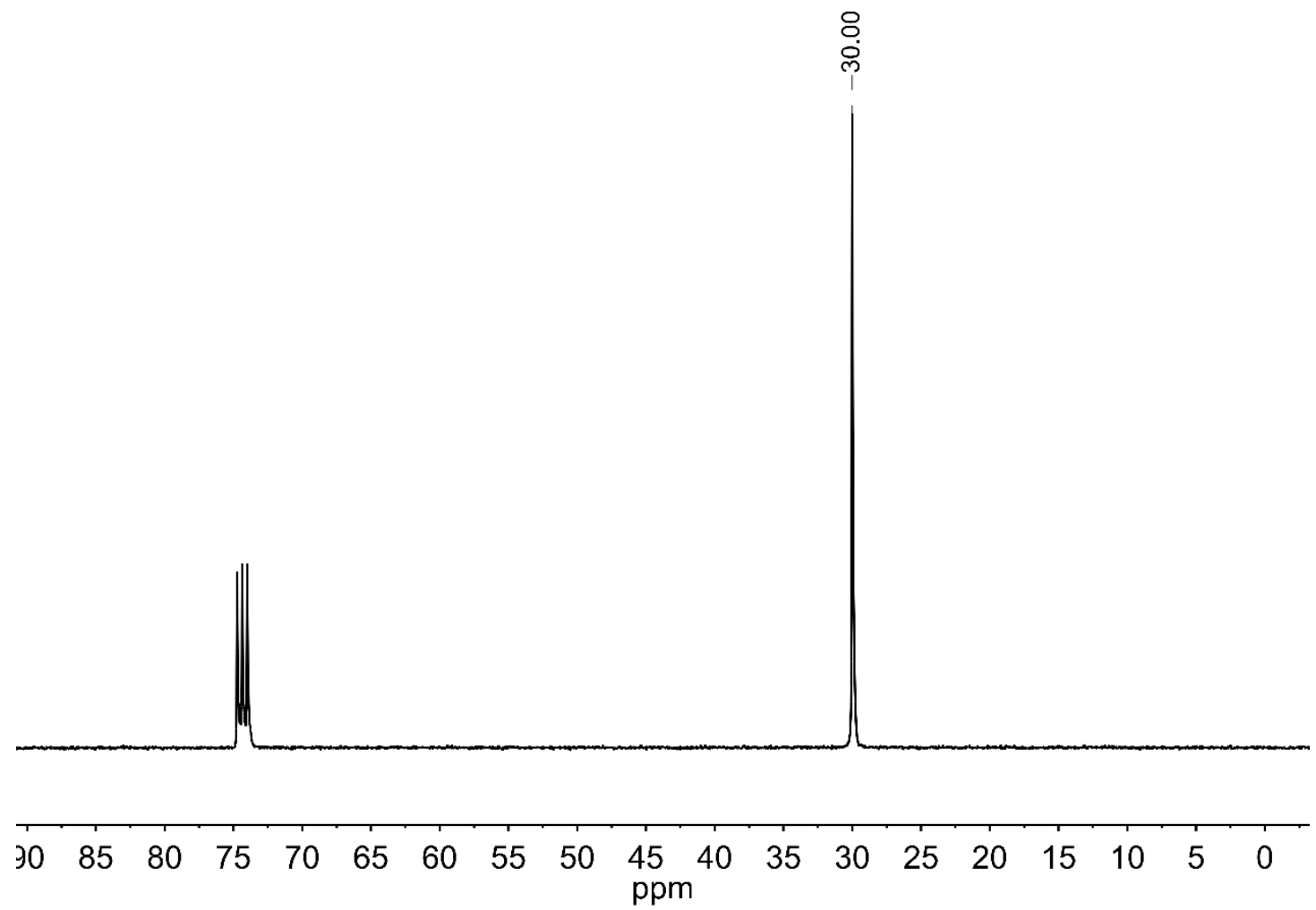

Figure $5{ }^{13} \mathrm{C}$ NMR spectrum of the polyethylene obtained using $\mathrm{Co3} / \mathrm{MAO}$ at $30{ }^{\circ} \mathrm{C}$ (entry 2, in Table 2); recorded in 1,1,2,2-tetrachloroethane- $d_{2}$ at $135^{\circ} \mathrm{C}(\delta \mathrm{C} 73.8)$. 


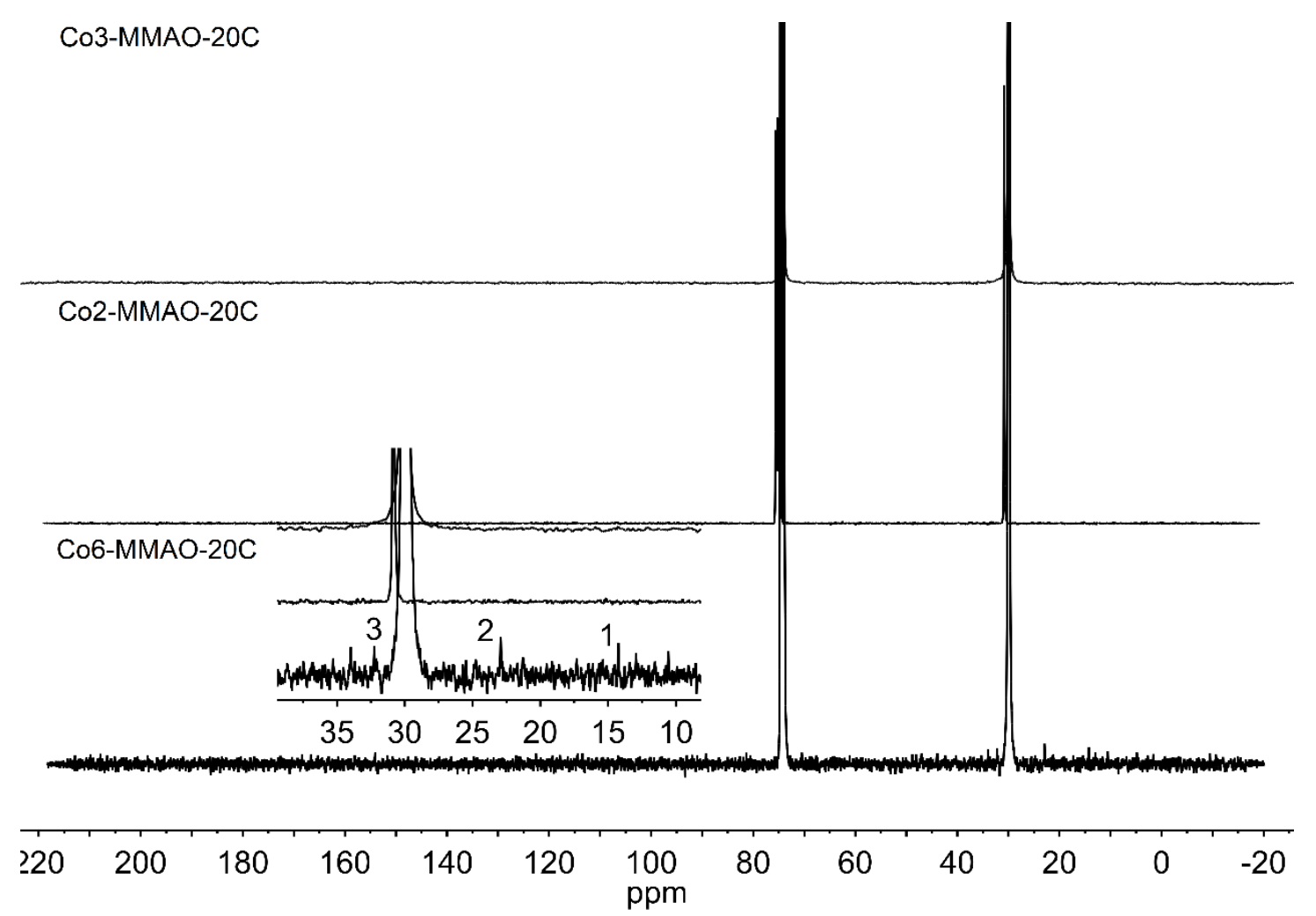

Figure $6{ }^{13} \mathrm{C}$ NMR spectra of the polyethylene obtained using a) Co3/MMAO b) Co2/MMAO and c) Co6/MMAO after 30 minutes at $20{ }^{\circ} \mathrm{C}$ (entries 3, 2, and 6, Table 3); all spectra recorded in 1,1,2,2tetrachloroethane- $d_{2}$ at $135^{\circ} \mathrm{C}(\delta \mathrm{C} 73.8)$.

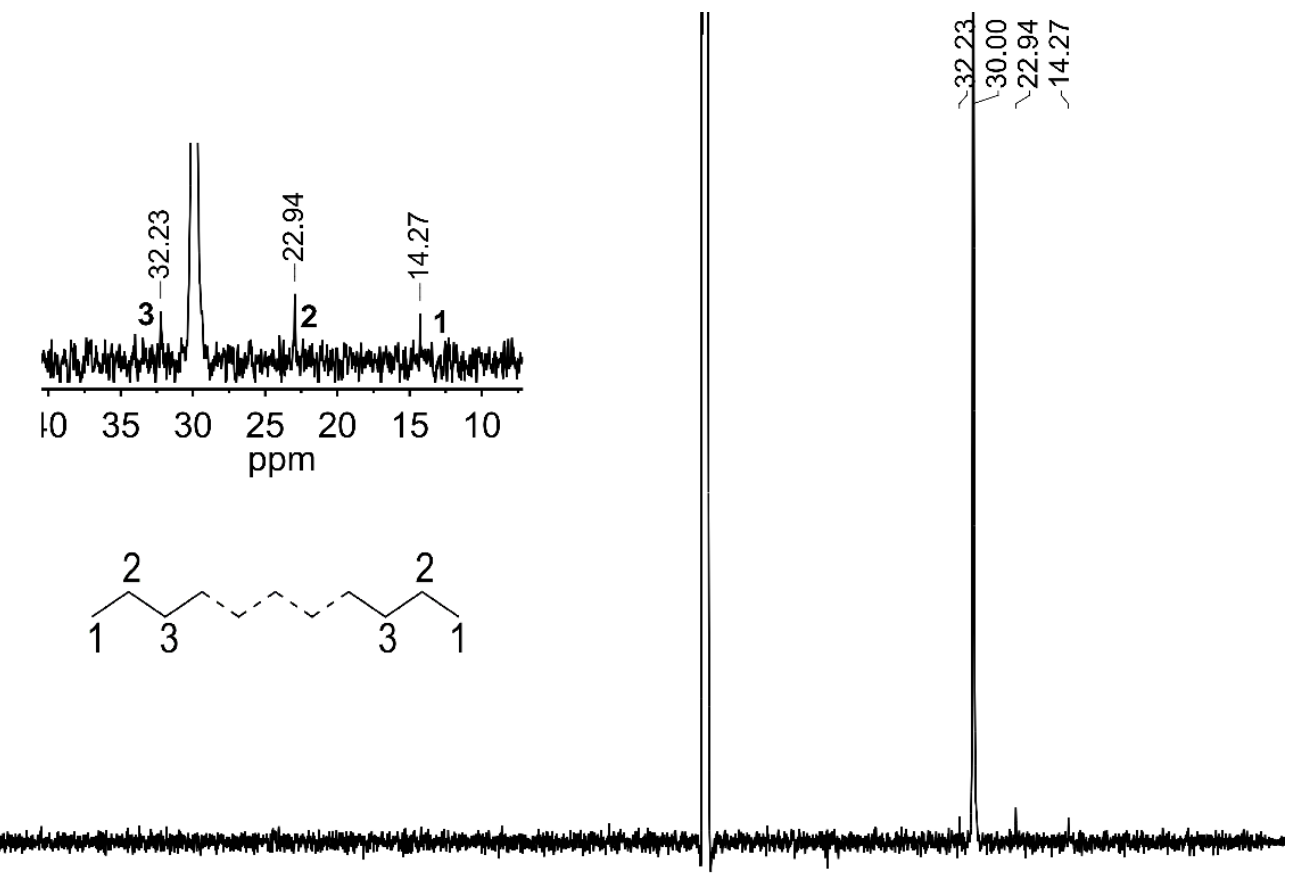

\begin{tabular}{|c|c|c|c|c|c|c|c|c|c|c|c|}
\hline 200 & 180 & 160 & 140 & 120 & $\begin{array}{l}100 \\
\mathrm{ppm}\end{array}$ & 80 & 60 & 40 & 20 & 0 & -2 \\
\hline
\end{tabular}

Figure $7{ }^{13} \mathrm{C}$ NMR spectrum of the polyethylene obtained with $\mathrm{Co3} / \mathrm{MMAO}$ at $60{ }^{\circ} \mathrm{C}$ (entry 5 , in Table $1)$; recorded in 1,1,2,2-tetrachloroethane- $d_{2}$ at $135^{\circ} \mathrm{C}(\delta \mathrm{C} 73.8)$. 
a)

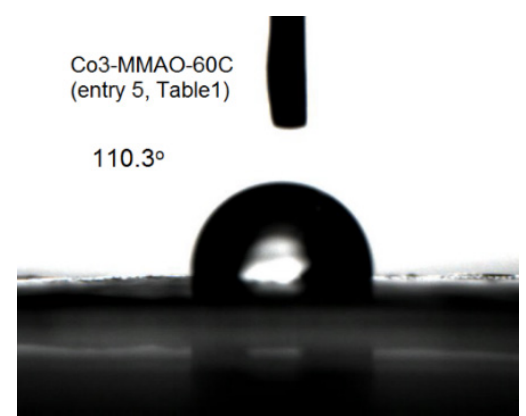

b)

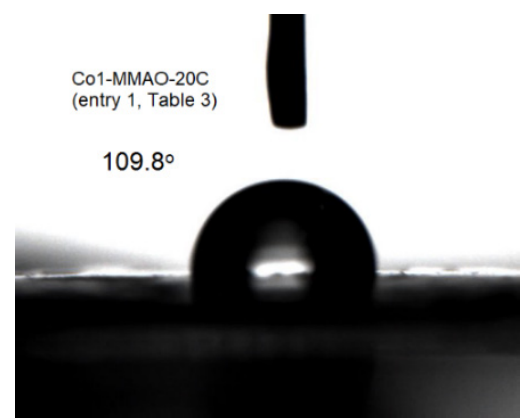

c)

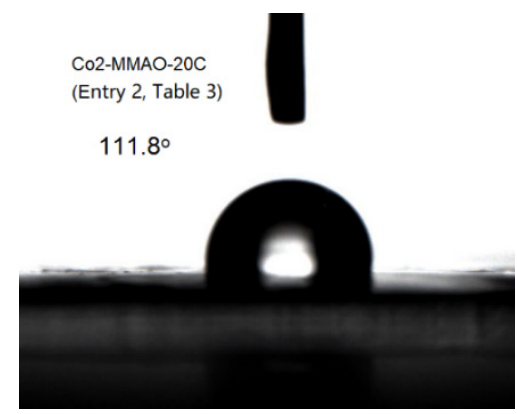

Figure 8 The water contact angles for the polyethylenes obtained using a) $\mathbf{C o 3} / \mathrm{MMAO}$ at $60^{\circ} \mathrm{C}, \mathrm{b}$ ) Co1/MMAO at $20^{\circ} \mathrm{C}$ and c) $\mathbf{C o 2} / \mathrm{MMAO}$ at $20^{\circ} \mathrm{C}$ 
Table 1 Ethylene polymerization by $\mathbf{C o 3} / \mathrm{MMAO}^{\mathrm{a}}$

\begin{tabular}{llllllll}
\hline Entry & $\mathrm{Al} / \mathrm{Co}$ & $\mathrm{T} /{ }^{\circ} \mathrm{C}$ & $\mathrm{t} / \mathrm{min}$ & Activity $^{\mathrm{b}}$ & $M_{\mathrm{w}}{ }^{\mathrm{c}}$ & $M_{\mathrm{w}} / M_{\mathrm{n}}{ }^{\mathrm{c}}$ & $T_{\mathrm{m}}{ }^{\mathrm{d}}$ \\
\hline 1 & 2000 & 20 & 30 & 1.91 & 48.5 & 3.15 & 134.5 \\
2 & 2000 & 30 & 30 & 1.39 & 45.7 & 3.54 & 133.9 \\
3 & 2000 & 40 & 30 & 1.31 & 31.5 & 3.91 & 133.2 \\
4 & 2000 & 50 & 30 & 0.71 & 20.6 & 4.23 & 132.9 \\
5 & 2000 & 60 & 30 & 0.27 & 16.2 & 4.23 & 130.7 \\
6 & 1000 & 20 & 30 & 0.98 & 61.4 & 2.14 & 134.3 \\
7 & 1500 & 20 & 30 & 1.27 & 59.4 & 2.36 & 133.9 \\
8 & 1750 & 20 & 30 & 1.56 & 55.6 & 2.39 & 133.8 \\
9 & 2250 & 20 & 30 & 1.40 & 42.6 & 3.81 & 133.9 \\
10 & 2500 & 20 & 30 & 1.30 & 50.5 & 2.74 & 134.4 \\
11 & 3000 & 20 & 30 & 1.16 & 53.8 & 2.50 & 134.8 \\
12 & 2000 & 20 & 15 & 2.00 & 43.5 & 3.23 & 132.9 \\
13 & 2000 & 20 & 45 & 1.33 & 49.4 & 2.61 & 134.9 \\
14 & 2000 & 20 & 60 & 1.05 & 52.4 & 2.59 & 134.7 \\
$15^{\mathrm{e}}$ & 2000 & 20 & 30 & 0.11 & 52.0 & 1.93 & 133.7 \\
\hline
\end{tabular}

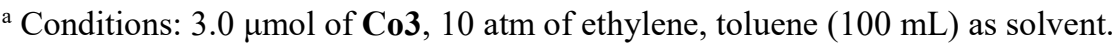

b Activity: $\times 10^{6} \mathrm{~g} \mathrm{PE} \mathrm{mol}^{-1}(\mathrm{Co}) \mathrm{h}^{-1}$.

${ }^{\mathrm{c}} M_{\mathrm{w}}$ in $\mathrm{kg} \mathrm{mol}^{-1} . M_{\mathrm{w}}$ and $M_{\mathrm{w}} / M_{\mathrm{n}}$ determined by GPC.

${ }^{\mathrm{d}}$ Determined by DSC.

e 1 atm of ethylene. 
Table 2 Ethylene polymerization by $\mathrm{Co3} / \mathrm{MAO}^{\mathrm{a}}$

\begin{tabular}{llllllll}
\hline Entry & $\mathrm{Al} / \mathrm{Co}$ & $\mathrm{T} /{ }^{\circ} \mathrm{C}$ & $\mathrm{t} / \mathrm{min}$ & Activity $^{\mathrm{b}}$ & $M_{\mathrm{w}}{ }^{\mathrm{c}}$ & $M_{\mathrm{w}} / M_{\mathrm{n}}{ }^{\mathrm{c}}$ & $T_{\mathrm{m}}{ }^{\mathrm{d}}$ \\
\hline 1 & 2000 & 20 & 30 & 1.13 & 53.2 & 2.43 & 134.7 \\
2 & 2000 & 30 & 30 & 1.21 & 49.1 & 2.25 & 133.9 \\
3 & 2000 & 40 & 30 & 0.84 & 36.3 & 3.12 & 133.2 \\
4 & 2000 & 50 & 30 & 0.79 & 27.6 & 3.76 & 132.4 \\
5 & 2000 & 60 & 30 & 0.41 & 18.2 & 3.59 & 131.7 \\
6 & 1000 & 30 & 30 & 0.85 & 57.3 & 3.07 & 135.8 \\
7 & 1250 & 30 & 30 & 1.12 & 52.3 & 2.12 & 133.6 \\
8 & 1500 & 30 & 30 & 1.35 & 52.0 & 2.18 & 134.3 \\
9 & 1750 & 30 & 30 & 1.20 & 50.2 & 2.07 & 133.8 \\
10 & 2500 & 30 & 30 & 1.18 & 48.0 & 2.44 & 134.3 \\
11 & 3000 & 30 & 30 & 0.97 & 46.7 & 2.48 & 133.3 \\
12 & 1500 & 30 & 15 & 1.80 & 47.5 & 2.50 & 134.8 \\
13 & 1500 & 30 & 45 & 1.14 & 52.7 & 2.70 & 134.5 \\
14 & 1500 & 30 & 60 & 0.91 & 64.3 & 1.89 & 133.6 \\
$15^{\mathrm{e}}$ & 1500 & 30 & 30 & 0.17 & 58.7 & 1.94 & 133.7 \\
\hline
\end{tabular}

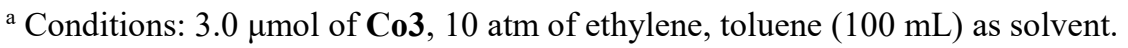

${ }^{\mathrm{b}}$ Activity: $\times 10^{6} \mathrm{~g} \mathrm{PE} \mathrm{mol}^{-1}(\mathrm{Co}) \mathrm{h}^{-1}$.

${ }^{\mathrm{c}} M_{\mathrm{w}}$ in $\mathrm{kg} \mathrm{mol}^{-1} . M_{\mathrm{w}}$ and $M_{\mathrm{w}} / M_{\mathrm{n}}$ determined by GPC.

d Determined by DSC.

e 1 atm of ethylene. 
Table 3 Ethylene polymerization using $\mathbf{C o 1}-\mathbf{C o 6}$ and Come2Ph $_{\text {using either MMAO or MAO }}{ }^{\text {a }}$

\begin{tabular}{llllllllll}
\hline Entry & Precat. & Co-cat. & $\mathrm{Al} / \mathrm{Co}$ & $\mathrm{T}^{\mathrm{T}} \mathrm{C}$ & Activity $^{\mathrm{b}}$ & $M_{\mathrm{w}}{ }^{\mathrm{c}}$ & $M_{\mathrm{w}} / M_{\mathrm{n}}{ }^{\mathrm{c}}$ & $T_{\mathrm{m}}{ }^{\mathrm{d}}$ & $\Delta H_{\mathrm{f}}\left(T_{\mathrm{m}}\right)^{\mathrm{d}}$ \\
\hline 1 & Co1 & MMAO & 2000 & 20 & 2.06 & 43.4 & 2.08 & 136.8 & 176.7 \\
2 & Co2 & MMAO & 2000 & 20 & 2.17 & 35.1 & 2.28 & 133.2 & 188.0 \\
3 & Co3 & MMAO & 2000 & 20 & 1.91 & 48.5 & 3.15 & 134.5 & 185.3 \\
4 & Co4 & MMAO & 2000 & 20 & 1.66 & 44.2 & 2.13 & 136.0 & 204.7 \\
5 & Co5 & MMAO & 2000 & 20 & 2.22 & 33.7 & 2.29 & 135.6 & 176.4 \\
6 & Co6 & MMAO & 2000 & 20 & 1.31 & 54.0 & 2.45 & 134.6 & 198.0 \\
7 & Coмe2Ph & MMAO & 2000 & 20 & 2.90 & 6.95 & 2.32 & 128.0 & 197.9 \\
8 & Co1 & MAO & 1500 & 30 & 1.90 & 34.4 & 2.20 & 133.5 & 204.6 \\
9 & Co2 & MAO & 1500 & 30 & 2.31 & 30.2 & 2.16 & 133.4 & 235.4 \\
10 & Co3 & MAO & 1500 & 30 & 1.35 & 52.0 & 2.18 & 134.3 & 188.7 \\
11 & Co4 & MAO & 1500 & 30 & 2.25 & 29.6 & 2.34 & 134.4 & 235.7 \\
12 & Co5 & MAO & 1500 & 30 & 2.50 & 38.9 & 1.86 & 135.3 & 199.8 \\
13 & Co6 & MAO & 1500 & 30 & 0.86 & 46.8 & 2.10 & 134.8 & 221.3 \\
14 & Coмe2Ph & MAO & 1500 & 30 & 5.25 & 12.1 & 1.76 & 130.1 & 177.2 \\
\hline
\end{tabular}

${ }^{\mathrm{a}}$ Conditions: $3.0 \mu \mathrm{mol}$ of precatalyst, MMAO or MAO as co-catalyst, $30 \mathrm{~min}$ run time, $10 \mathrm{~atm}$ of ethylene and toluene $(100 \mathrm{~mL})$ as solvent.

${ }^{\mathrm{b}}$ Activity: $\times 10^{6} \mathrm{~g} \mathrm{PE} \mathrm{mol}^{-1}(\mathrm{Co}) \mathrm{h}^{-1}$.

${ }^{\mathrm{c}} M_{\mathrm{w}}$ in $\mathrm{kg} \mathrm{mol}^{-1} \cdot M_{\mathrm{w}}$ and $M_{\mathrm{w}} / M_{\mathrm{n}}$ determined by GPC.

${ }^{\mathrm{d}}$ Determined by DSC. 